\title{
PEREC, Georges. Tentativa de esgotamento de um local parisien- se. Tradução de Ivo Barroso. São Paulo: G. Gili, 2016, 60 p.
}

Manlio de Medeiros Speranzini* Universidade Federal de Minas Gerais

No ano de 2016, quando o escritor francês Georges Perec (1936 1982) completaria 80 anos, a editora Gustavo Gili publica o livro Tentativa de esgotamento de um local parisiense, obra que já havia recebido uma primeira tradução portuguesa em 1977 com o título Leitura exaustiva de um lugar parisiense - ou as ruínas de Paris, quando fora incluída no livro $O$ aprodrecimento das sociedades [Le pourssissement des sociétés] (1975), coletânea de textos do grupo Cause Commune. Acostumado até agora com seus romances, o leitor brasileiro da obra perecquiana não havia tido até esse momento um contato com seus trabalhos experimentais ou reflexivos sobre o espaço. Se existe uma diferença marcante entre essa obra e as outras já publicadas no Brasil é que nela desaparece o romanesco - a

\footnotetext{
* Pós-Doutor do Programa de Pós-Graduação em Estudos Literários (Pós-Lit), FALE/ UFMG, Linha de pesquisa: Literatura, outras artes e mídias. Doutor em Letras pelo Programa de Pós-Graduação em Estudos Linguísticos, Literários e Tradutológicos em Francês da Faculdade de Filosofia, Letras e Ciências Humanas da Universidade de São Paulo (FFLCH/USP, 2011). Atualmente pesquisa acadêmica tem seus interesses no campo da Literatura, outras Artes e Mídias, em especial em trabalhos que envolvem Literatura Francesa e Arte Contemporânea com foco na relação texto/imagem em poéticas que tratam do Cotidiano, do Espaço e dos Objetos. Belo Horizonte, Minas Gerais, Brasil. Email: manliosperanzini@ gmail.com.
} 
fábula, os personagens, os diálogos - para tratar do que ele mesmo chama de "o resto".

Georges Perec tem uma obra literária diversificada que abrange romances, crônicas, poesias, roteiros para cinema, peças para rádio e teatro, palavras cruzadas, etc., e que foi gerada por aquilo que esse autor chamava de seus quatro campos de cultivo, ou, de seus quatro modos de propor o mesmo questionamento segundo diferentes perspectivas: o autobiográfico, o ficcional, a linguagem e o mundo ao redor. A divisão proposta por Perec não é estanque e tudo o que ele escreveu resultou de alguma maneira da fusão indistinta desses quatro campos. Tentativa de esgotamento de um local parisiense (TELP) ${ }^{1}$ é um exemplo disso.

Ainda que essa obra possa ser definida como um exercício de descrição, ela está longe de ser uma écfrase paisagística na qual o texto instigaria o leitor a ver de maneira potente pela janela da escrita a imagem viva e pulsante da cidade, muito pelo contrário, e TELP, num primeiro momento, parece ser o relatório de um analista de trânsito.

Se essa obra não corresponde a nenhum gênero literário específico, ela cumpre um programa de escrita claramente definido por Perec no preâmbulo do livro quando ele explica que seu objetivo é o de descrever "o que não tem importância" (TELP, 2016, p. 11). Para ajudar a entender a natureza dessa experiência, as indicações mais eficazes advêm de três frentes de trabalho do autor: os grupos Oulipo e Cause Commune e o livro Espèces d'Espaces [Espécies de Espaços] (1974).

O Oulipo, grupo criado por Raymond Queneau e François Le Lionnais em 1960, tinha por objetivo recuperar, estudar, atualizar e

${ }^{1}$ A partir de agora, o livro que é objeto desta resenha passará a ser identificado pela sigla “TELP”, acrescido do ano "2008” para a edição francesa e "2016" para a edição brasileira. 
criar procedimentos de escrita que, descartando qualquer noção de inspiração e de acaso, fazia uso de regras - chamadas por eles de contraintes [restrições] - como estímulos produtivos controláveis de uma expressão contemporânea (BELLOS, 1994, p. 368-372). Mas se as contraintes serviam ao Oulipo como uma força propulsora da escrita, Perec as levou para um momento anterior à própria escrita quando determinou para si uma série de regras que guiariam seu olhar pelo mundo para "ver diferente".

Já o grupo Cause Commune, criado em 1972 por Jean Duvignaud, Paul Virilio e pelo próprio Perec, tinha por objetivo, entre outras preocupações, empreender uma antropologia do homem contemporâneo por meio de uma investigação ampla da vida cotidiana e uma discussão sobre atitudes e teorias (BELLOS, 1994, p. 510515). A posição de Perec frente às preocupações do grupo pode ser encontrada no editorial Approches de quoi? [Aproximações de quê?] (1973) (PEREC, 1989) onde ele questiona a natureza do cotidiano e as estratégias necessárias para percebê-lo, interrogá-lo e descrevê-lo. Para deixar o estado de apatia que encobre tudo o que se refere aos nossos hábitos, Perec proclama a fundação de uma antropologia particular que trataria daquilo que nos é mais próximo e para isso pedia: "descreva a sua rua. Descreva outra. Compare-as” (PEREC, 1989, p. 12).

Mas as indicações mais eficazes para a compreensão de TELP estão no livro Espèces d'Espaces - obra que ele designava como "o diário de um usuário do espaço". No capítulo "la page” [a página] Perec (1994, p. 19) afirma que ao escrever ele habita sua folha de papel e que nesse movimento de exploração e ocupação ele suscita vazios, espaços, "saltos no sentido: descontinuidades, passagens, transições”. O espaço da escrita para ele começava então assim: "somente com palavras, signos traçados sobre a página branca" (PEREC, 1994, p. 21), fazendo de cada página uma ocupação única que se efetiva através das escolhas que estruturam o texto, selecionam um vocabulário e definem os traços a serem deixados 
ali. Já no capítulo "la rue” [a rua], Perec apresenta o que chama de “Travaux pratiques” [Trabalhos práticos] (1994, p. 70-74), uma série de exercícios através das quais o autor incita o leitor a observar a rua de maneira sistemática, lenta e minuciosa, anotando aquilo que vê em detalhes, mesmo que isso pareça tolo e sem sentido. E por fim, ainda no mesmo capítulo, Perec apresenta um projeto de escrita que vinha desenvolvendo desde 1969 chamado "Les lieux" [Os lugares] (1994, p. 76-77) e para o qual ele havia escolhido doze lugares na cidade de Paris que pretendia visitar ao longo de doze anos. Por meio de descrições feitas in loco e de lembranças de cada um dos doze lugares ele pensava compor pela escrita "cápsulas do tempo" que conteriam as marcas de um triplo envelhecimento: o dos lugares, o das lembranças e da sua própria escrita. De certa forma, TELP explora e condensa todas as iniciativas relatadas acima.

TELP trata de um levantamento feito por Perec ao longo dos dias 18, 19 e 20 de outubro de 1974 na praça Saint-Sulpice, em Paris, para descrever "aquilo que em geral não se nota, o que não tem importância: o que acontece quando nada acontece, a não ser o tempo, as pessoas, os carros e as nuvens." (TELP, 2016 , p. 11). Após uma pequena introdução na qual o autor explica seu propósito, o livro se divide em três partes - uma para cada dia do projeto - nas quais se distribuem as nove sessões de escrita feitas in loco.

Ainda que as informações dadas a seguir relativas à materialidade do texto de Perec em TELP não digam respeito ao trabalho da tradução, elas são importantes para que se entenda como a percepção do infraordinário no mundo acaba por migrar para a página impressa, conferindo ao texto dessa obra um caráter visual com marcas muito particulares que, embora sutis e ambíguas (e por isso mesmo do campo do infraordinário), geram questionamentos e interferem na maneira como o texto é apreendido pelo leitor. 
Na edição francesa (Fig. 1 e 3), cada uma das partes do livro está identificada por algarismos romanos: I, II e III, enquanto que cada uma das nove seções de observação da praça está indicada por números arábicos, sendo assim distribuídas: 1 a 4 na parte I, 5 a 7 na parte II, e 8 e 9 na parte III. Cada uma das nove sessões tem como cabeçalho três ou quatro linhas com a indicação de: data, hora, lugar (de onde se observa a praça) e, algumas vezes, tempo (as condições climáticas). Todo o texto é escrito numa única tipografia com serifa, sem o uso de negrito ou de frases em maiúsculas; o alinhamento do texto é justificado, abrindo espaços em branco quando as frases são muito curtas ou quando existem alíneas; ainda que algumas palavras e frases apareçam em itálico, é difícil identificar uma norma para isso; o uso da pontuação é totalmente errático, ora obedecendo às normas gramaticais, ora sendo totalmente abolido; as alíneas também ocorrem de maneira irregular, criando vazios entre as manchas de texto que, em alguns momentos principalmente quando as linhas de texto começam em minúsculas (Fig. 1) -, fazem pensar em apagamentos ou silêncios. 
TENTATIVE D'EPUISEMENT D'UN LIEU PARISIEN

Un car, vide.

d'autres Japonais dans un autre car

Le 86 va à Saint-Germain-des-Prés

Braun reproductions d'art

Accalmie (lassitude ?)

Pause.

2

la date : 18 octobre 1974

l'heure : $12 \mathrm{~h} 40$

le lieu : Café de la Mairie

plusieurs dizaines, plusieurs centaines d'actions simultanées, de micro-événements dont chacun implique des postures, des actes moteurs, des dépenses d'énergie spécifiques

discussions à deux, discussions à trois, discussions à plusieurs : le mouvement des lèvres, les gestes, les mimiques expressives

modes de locomotion : marche, véhicule à deux roues (sans moteur, à moteur), automobiles (voitures privées, voitures de firmes, voitures de louage, auto-école), véhicules utilitaires, services publics, transports en commun, cars de touristes

modes de portage (à la main, sous le bras, sur le dos)

modes de traction (cabas à roulettes)
A DATA: 18 DE OUTUBRO DE 1974

A HORA: 12.40

O LOGAL: CAFÉ DE LA MAIRIE várias dezenas, várias centenas de ações simultâneas, de microacontecimentos, cada um dos quais implicando posturas, atos motores, dispêndio de energia específicos:

discussões de dois, discussões de três, discussões de vários: o movimento dos lábios, os gestos, as mímicas expressivas

modos de locomoção: caminhando, em veículos de duas rodas (sem motor a motor), automóveis (carros particulares, carros empresariais, carros de alugue autoescolas), voiculos utiltarios, do serviço público, transporte comunitário, ônibus de turismo

maneiras de carregar (na mão, embaixo do braço, às costas)

modos de tração (carrinho de compras)

graus de determinação ou de motivação: esperar passear, arrastar, errar, ir, correr para, precipitar-se (em direção a um táxi livre, por exemplo), procurar, zanzar, hesitar, caminhar com passo decidido

posições do corpo: sentado (nos ônibus, nos carros, nos cafés, nos bancos)

Figura 2 - Tentativa de esgotamento de um local parisiense, 2016 , p. 20

Observam-se várias alterações na edição brasileira (fig. 2 e 4) quanto à materialidade do texto se comparada à edição francesa, por exemplo: o emprego de uma tipografia sem serifa; o alinhamento à esquerda do texto e um espaçamento maior entre os parágrafos; a identificação com algarismos arábicos das sessões foi abolida, cancelando assim o que ajuda a identificar e a localizar cada sessão na cronologia do trabalho; os cabeçalhos das sessões aparecem em maiúsculo e em negrito; o uso do itálico não segue a edição francesa e, em três momentos (TELP, 2008, p. 12, 13 e 35), palavras e frase em itálico no texto de partida aparecem grafadas em romano, maiúsculo e negrito no texto de chegada (TELP, 2016, p. 15, 16 e 43); quanto às alíneas, a edição brasileira acompanha boa parte da edição francesa, apresentando 
divergências nas páginas 20 (Fig. 2), 21 e 34 (TELP, 2016); a edição brasileira ainda inclui um elemento estranho à edição francesa: pequenas ilustrações que pontuam o texto representando: ônibus (TELP, 2016, p. 13 e 39), bicicleta (TELP, 2016, p. 41 e 53) e pássaros (TELP, 2016, p. 55 e 62). Ainda que todas essas mudanças não alterem o sentido das palavras do texto, elas acrescentam eventos gráficos que são da ordem do extraordinário (o negrito, o maiúsculo, as ilustrações, etc.) ou que amplificam a irregularidade do texto - como ocorre com a margem do texto não alinhado à direita da página (Fig. 2 e 4) -, distraindo o olhar do leitor e dificultando a percepção das nuances da escrita perecquiana - que é da ordem do sutil e da invisibilidade (exatamente como o infraordinário).

TENTATIVE D'EPUISEMENT D'UN LIEU PARISIEN

\section{Quelques enfants}

Quelques cabas à roulettes

Une deux-chevaux dont le pare-brise s'orne d'un caducée conduite par un vieux monsieur se range au bord du trottoir ; le vieux monsieur vient chercher dans le café une vieille dame qui buvait un café en lisant Le Monde

Passe une femme élégante tenant, tiges en haut, un grand bouquet de fleurs.

Passe un 63

Passe une petite fille qui porte deux grands sacs à provisions

Un oiseau vient se poser sur le sommet d'un lampadaire

Il est midi

Bourrasque

Passe un 63

Passe un 96

Passe une deux-chevaux vert pomme

La pluie devient violente. Une dame se fait

un chapeau avec un sac en plastique marqué

"Nicolas "

Des parapluies s'engouffrent dans l'église

Instants de vide

Passage d'un autobus 63

45

Figura 3 - Tentative d'épuisement d'un lieu parisien, 2008, p. 45
Passa uma senhora elegante levando, talos para cima, um grande buquê de flores.

Passa um 63

Passa uma menina carregando dois grandes sacos de provisões

Uma pomba acaba de pousar no alto de um poste

É meio-dia

Chuvarada

Passa um 63

Passa um 96

Passa um dois-cavalos verde-maçã

A chuva se torna violenta. Uma senhora faz um chapéu com um saco plástico marcado "Nicolas"

Guarda-chuvas precipitam-se para a igreja

Instantes de vazio

Passagem de um ônibus 63

Geneviève Serreau passa diante do café (longe demais de mim para que lhe possa fazer um sinal)

Projeto de uma classificação de guarda-chuvas segundo as formas, os modos de funcionamento, as cores, os materiais...

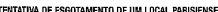
67

Figura 4 - Tentativa de esgotamento de um local parisiense, 2016, p. 57 
Sobre a presença da voz do tradutor em TELP, ela se dá de duas maneiras: por meio do uso de colchetes e pela inserção de notas de rodapé. Os colchetes aparecem nas frases: "no $6^{\circ}$ arrondissement [bairro] de Paris" (TELP, 2016, p. 14), "[citroën] méhari verde" (TELP, 2016, p. 17) e "uma lata de Ripolin [tinta]" (TELP, 2016, p. 53). Se o uso dos colchetes parece ser improdutivo devido a seu pequeno número e inadequado por inserir um sinal gráfico que se confunde com o uso frequente que Perec faz dos parênteses, é nas dez notas de rodapé onde se evidencia a fragilidade da mediação entre o texto de partida e o de chegada.

Se, de um lado, há duas notas de rodapé para informar o sentido das siglas O.R.T.F. - "Repartição da Rádiodifusão e da Televisão Francesa" (TELP, 2016, p. 16, nota $n^{0}$ 1) e S.C.N.F - "Sociedade Nacional de Estradas de Ferro" (TELP, 2016, p. 24, nota ${ }^{\circ} 3$ ), de outro lado, a sigla R.A.T.P. (Régie Autonome des Transports Parisiens) que aparece nas frases: "contrôleur de lignes à la R.A.T.P." (TELP, 2008, p. 32), e "si la R.A.T.P. l'appointe pour les dénombrer..." (TELP, 2008, p. 39) é substituída por duas expressões distintas e genéricas nas traduções "controlador das linhas de ônibus" (TELP, 2016, p. 39), e "se o serviço de trânsito o contratou para contá-los...” (TELP, 2016, p. 48).

Já a nota $\mathrm{n}^{\circ} 4$ se refere ao termo "palmier" presente na frase "Une jeune fille mange la moitié d'un palmier" (TELP, 2008, p. 20) e que foi traduzida como "Uma jovem come a metade de uma palmeira” (TELP, 2016, p. 25) - necessitando então da explicação dada na nota: "No original, palmier, que significa também biscoito amanteigado." Teria sido mais esclarecedor e, principalmente, mais coerente para com as estratégias já adotadas pela tradução, que o termo "palmier" fosse mantido intacto no texto de chegada e que a explicação "um biscoito amanteigado" aparecesse entre colchetes ou em nota de rodapé, sem a necessidade de traduzir literalmente o nome do biscoito. 
Como última observação sobre a voz do tradutor em TELP, na nota $\mathrm{n}^{0} 8$, referente à frase "Duas berinjelas gaiatas" (TELP, 2016, p. 32), tradução de “Deux aubergines toniques” (TELP, 2008, p. 26), o tradutor justifica o uso que Perec faz da palavra "aubergine" [berinjela] - e que reaparece em outros dois momentos do texto (TELP, 2008, p. 50 e 51) - explicando que: "Perec alude à moda "avançada" de então, quando as jovens usavam roupas de cores gritantes." (TELP, 2016, p. 32). Mas o que justificaria a presença de "berinjelas" na praça Saint-Sulpice naquela época é que, além de designar o legume, essa palavra identificava as fiscais de trânsito da prefeitura que eram chamadas assim por causa da cor dos seus uniformes ${ }^{2}$.

Tentative d'épuisement d'um lieu parisien guarda na escrita uma sincronia entre o ver e o escrever que, para se efetivar, exigiu de Perec um vocabulário reduzido e objetivo que faz uso de siglas, nomes próprios, marcas comerciais, gírias e jargões que, exaustivamente repetidos, são sinais do olhar investigativo do autor, de um tempo e de uma cultura. Dentre as opções da tradução que, nesse contexto, afastam o leitor das sutilezas do texto perecquiano vale destacar, inicialmente, certos apagamentos como:

A palavra "mairie", no contexto da cidade de Paris, designa um órgão da municipalidade equivalente a uma subprefeitura. Quando o termo "mairie" é traduzido por "câmara municipal" (TELP, 2016, p. 11), ou simplesmente "câmara" (TELP, 2016, p. 21, 25 e 27), sem qualquer outra explicação, o leitor brasileiro deixa de relacionar a presença desse prédio público na praça Saint-Sulpice com o "Café de la Mairie" (TELP, 2016, p. 20, 34, 44 e 48) (Fig. 1 e 2) - um dos pontos de observação utilizados por Perec para descrever/escrever - e mantido em francês no texto de chegada. Da mesma forma que "palmier", citada anteriormente, essa palavra

${ }^{2}$ Cf. Tenue d'uniforme des Auxiliaires de Police de la Préfecture de Police de 1964 à 1993. In : Catalogues. Uniforme des Auxiliaires de Police. Les Auxiliaires de Police. Disponível em: < http://amicale-police-patrimoine.fr/>. Acesso em 29 out. 2016.

Cad. Trad., Florianópolis, v. 37， no 3， p. 379-391, set-dez 2017 
poderia ter sido mantida em francês no texto traduzido acrescida de uma nota do tradutor;

A palavra "Vittel" - marca famosa de água mineral - presente nas frases "Je bois un vittel" (TELP, 2008, p. 35) e "et semble s'étonner de me voir encore attablé devant un vittel” (TELP, 2008, p. 36) também é apagada do texto de chegada e substituída por um nome genérico: "Bebo uma mineral" (TELP, 2016, p. 43), e "parece espantar-se por me ver ainda sentado diante de uma água mineral” (TELP, p. 2016, p. 44);

"Vieux Marc", um tipo de bebida destilada feita com o bagaço da uva, que aparece nas frases: "j'ai froid ; je commande un vieux marc" (TELP, 2008, p. 25), e “Je commande un marc" (TELP, 2008, p. 42), recebeu dois tratamentos: primeiro foi traduzida por um termo genérico (exatamente como no caso anterior): "estou com frio; peço uma aguardente" (TELP, 2016, p. 31), e, segundo, foi substituída de maneira inusitada por um objeto: "Peço um martelo" (TELP, 2016, p. 51). Melhor seria que se mantivesse o nome da bebida em francês;

"bourgueil", que designa um tipo de vinho de origem controlada e aparece nas frases: "J'ai mangé une paire de saucisses en buvant un ballon de bourgueil" (TELP, 2008, p. 24) e "j'ai mangé un sandwich au saucisson en buvant un ballon de bourgueil" (TELP, 2008, p. 38), recebe tratamentos distintos na tradução: "Comi um par de salsichas e bebi uma taça de bourgueil" (TELP, 2016, p. 30) e "comi um sanduíche de salsichão com um copázio de vinho" (TELP, 2016, p. 47);

O edifício mais imponente da praça é a igreja de Saint-Sulpice e entre ela e a praça há o adro da igreja ("le parvis", em francês); sempre que o adro é mencionado no original ele indica, primeiro, a direção do olhar de Perec e, segundo, a identificação de um espaço onde há uma série de eventos que ocorrem muito em função 
da igreja; esse lugar é mencionado, por exemplo, na frase: "une femme traverse en courrant le parvis de l'église” (TELP, 2008, p. 16), traduzida como "uma mulher atravessa correndo o adro da igreja" (TELP, 2016, p. 21); mas, se na frase anterior esse lugar foi precisamente identificado na tradução, o mesmo não ocorre em outros momentos como nas frases: "Le parvis est quasi vide" (TELP, 2008, p. 46), "Un homme [...] traverse très lentement le parvis" (TELP, 2008, p. 47), e “Le parvis est vide” (TELP, 2008, p. 50), que foram traduzidas como : “A praça está quase vazia" (TELP, 2016, p. 58), “Um homem [...] atravessa a praça bem lentamente" (TELP, 2016, p. 58) e "A praça está vazia" (TELP, 2016, p. 62). Na troca da palavra "adro" por "praça”, a tradução não só altera a abrangência do campo de visão do autor, como estabelece uma equivalência direta entre o que ocorre no adro e na praça - o que não é possível afirmar.

Sobre os desvios da tradução, vale destacar:

Perec apresenta no início do texto uma lista de categorias de coisas estritamente visíveis na praça: “- Des lettres de l'alphabert, des mots [...] / - Des symboles conventionnels [...] / - Des chiffres [...] / - Des solgans fugitifs [...] / - De la terre [...] / - De la pierre [...] / - De l'asphalte / - Des arbres [...]" (TELP, 2008, p. 10-11) etc., e que foi traduzida como: "- Algumas letras do alfabeto, palavras [...] / - Alguns símbolos convencionais [...] / - Algumas cifras [...] / - Slogans que passam [...] / - Vejo o chão [...] / - Vejo as pedras [...] / - O asfalto / - Árvores [...]" (TELP, 2016, p.14-15). Além de incluir o pronome indefinido "alguns/algumas" em três categorias da lista, a tradução ainda introduz um narrador em primeira pessoa quando, para acompanhar a natureza objetiva, repetitiva e econômica do texto de partida, seria mais adequado que a lista simplesmente indicasse: "- Letras do alfabeto, palavras [...] / Símbolos convencionais [...] / - Números [...] / - Slogans fugitivos [...] / - Terra [...] / - Pedra [...] / Asfalto / Árvores [...]”; 
A expressão "genre Milou" presente nas frases "un enfant fait courrir son chien (genre Milou)" (TELP, 2008, p. 17) e "deux frères chiens genre Milou” (TELP, 2008 p. 26) e traduzida por: "raça Milu" (TELP, 2016, p. 22 e p. 33), acompanharia mais adequadamente o texto de origem se fosse traduzida como "tipo Milou" já que, ao invés de indicar uma raça de cachorros, ela aponta uma semelhança daqueles cachorros com "Milou" - o cachorro do personagem de histórias em quadrinho Tintin;

Ainda que o primeiro sentido da palavra "bière" seja "cerveja”, a frase "On sort la bière. Le tocsin se remet à sonner" (TELP, 2008, p. 23) e traduzida como "Descarregam a cerveja. O sino de rebate volta a tocar" (TELP, 2016, p. 28), guarda outro sentido: "Sai o caixão. O sino do rebate volta a tocar"; esse sentido é reforçado pelo que é descrito pouco antes: "Saem da igreja as coroas mortuárias" (TELP, 2016, loc. cit.) e por aquilo que vem logo após a retomada do rebate do sino: "O carro fúnebre segue [...]" (TELP, 2016, p. 29);

Já quando Perec se refere a "un demi" na frase "qu'un consommateur commande un café plutôt qu'un demi...” (TELP, 2008, p. 28), traduzida como "que um cliente peça um café em vez de um pequeno..." (TELP, 2016, p. 35), ele quer dizer "uma cerveja";

A frase "passent des ouatures" (TELP, 2008, p. 32) traduzida como "passam chumaços voando" (TELP, 2016, p. 39), indica mais precisamente "passam carrões" (ou outra gíria para identificar "carros");

Quanto à frase "une voiture surbaissée” (TELP, 2008, p. 26), traduzida como "um carro acidentado" (TELP, 2016, p. 32), ela identifica na verdade "um carro rebaixado";

A frase "avec leurs cargaisons de Japonais photophages" (TELP, 2008 p. 34), traduzida como "com seu carregamento de japoneses 
fotógrafos" (TELP, 2016, p. 43), seria mais bem traduzida por "com seus carregamentos de Japoneses fotófagos";

A frase "Plusieurs femmes en camaïeus de verts" (TELP, 2008, p. 40), traduzida como "Várias mulheres em camafeus de verde" (TELP, 2016, p. 49), seria mais bem compreendida se traduzida como "Várias mulheres em tons de verde";

E, por fim, a frase "Des gens des gens des voitures" (TELP, 2008, p. 43), traduzida como "Multidões de gente e de automóveis" (TELP, 2016, p. 53), deveria, para acompanhar o incomum da construção da frase em francês, ser mantida numa tradução literal de três frases consecutivas sem qualquer conectivo ou sinal de pontuação: "Pessoas pessoas carros".

Sob o domínio da visualidade, TELP é um texto de valor fotográfico que concentra os esforços de observação do escritor sobre o espaço e seu gesto de dar permanência pela escrita ao que ali é passageiro e sem importância. O vocabulário de TELP é marcado por termos e expressões que acumulam sentidos particulares e que, na opção de serem traduzidos ou permanecerem estrangeiros no texto de chegada, exigiriam uma presença mais atenta e coerente por parte do tradutor - o mediador mais qualificado para o intraduzível da cultura. Além disso, se a edição analisada parecia competente em vários momentos ao acompanhar a visualidade do texto perecquiano, o confronto direto com o original francês revelou um direcionamento equivocado que interfere e desvia nosso olhar do que se encontra ali de mais importante: o desimportante.

Recebido em:13/02/2017

Aceito em: 25/05/2017

Publicado em setembro de 2017 